\title{
Adapted versus Projected Machining Centers Energy Consumption for MQL Technique
}

\author{
Augusto Dttmann ${ }^{1}$, Jefferson de Oliveira Gomes ${ }^{2}$ \\ ${ }^{1}$ Department of Mechanical Engineering, Aeronautics Institute of Technology (ITA), Marechal \\ Eduardo Gomes 50, São José dos Campos 12228-900, Brazil (augusto@ita.br) ORCID 0000- \\ 0003-2264-8572; '2Department of Mechanical Engineering, Aeronautics Institute of \\ Technology (ITA), Marechal Eduardo Gomes 50, São José dos Campos 12228-900, Brazil \\ (gomes@ita.br) ORCID 0000-0002-6004-799x
}

\begin{abstract}
Cutting fluid application is a vital technique to achieve the expected result in most machining processes. However, besides having a high cost, the cutting fluid application also represents a risk to the environment due the oil chemical characteristics. The Minimum Quantity Lubrication (MQL) is an alternative when looking for reduction of oil consumption and a more environmentally friendly process. A literature review has shown that many predictive models of machine tool power consumption do not consider the consumption of the required air compressor in MQL. This paper's motivation was testing these models to predict the energy consumption. It was observed that the amount of consumed energy in the cutting is lower when compared to the consumption of basic components of the machining center in both cases. Using the MQL, the tool life showed a decrease. However, it allows the feed to increase and reduces the energy consumption.
\end{abstract}

Author Keywords. Manufacturing, Machining, MQL, Energy.

Type: Research Article

○ Open Access $\square \mathbf{~}$ Peer Reviewed $@$ CC BY

\section{Introduction}

Manufacturing is the most influential industry sector in the world economy (Hamran et al. 2020). Among the production processes, machining stands out as being one of the main discrete manufacturing process (Sharma, Dogra, and Suri 2009; Dttmann and Gomes 2019). In the industry, the machining process is planned to provide the best quality or the lowest cost possible (Umbrello, Micari, and Jawahir 2012).

Machining features high financial and environmental costs (Sharma, Dogra, and Suri 2009; Hamran et al. 2020). Over the decades, quality requirements, increased productivity and development of new tools have been the object of research studies (Fratila and Caizar 2012). Studies show that one of the main financial costs of machining is the application of cutting fluid, which can correspond up to $20 \%$ of the total cost (Ekinovic, Prcanovic, and Begovic 2015; Klocke and Eisenblätter 1997). In addition, chemical additives, applied with the intention to reduce the bacteria growth in the cutting fluids, can cause damage to human health and environmental problems in disposal (Khunt et al. 2020).

It is currently possible to identify an increase in studies with the aim of developing a more sustainable process (Fratila and Caizar 2012; Gaurav et al. 2020; Sarikaya and Güllü 2014). This new direction of research is motivated by the increase in environmental regulations and the increasing cost pressure in the manufacturing industry (Fratila and Caizar 2012).

The Minimum Quantity Lubrication (MQL) is an alternative when looking for reduction of oil consumption and a more environmentally friendly process (Gaurav et al. 2020; Hamran et al. 
2020). Furthermore, there are authors who defend the improvement of machining force, tool life increase and energy consumption decrease due to the withdrawal of the high pressure pump from the flood system, although there are divergences.

This paper aims to study the energy consumption in a comparative manner between one technique in two machining center, one adapted for MQL and another center designed to use the technique. During the study, tool life and cutting forces were also measured. The machining process chosen was the through-hole in gray cast iron.

\section{Materials and Methods}

The tests in this paper were performed according to the flowchart presented in Figure 1.

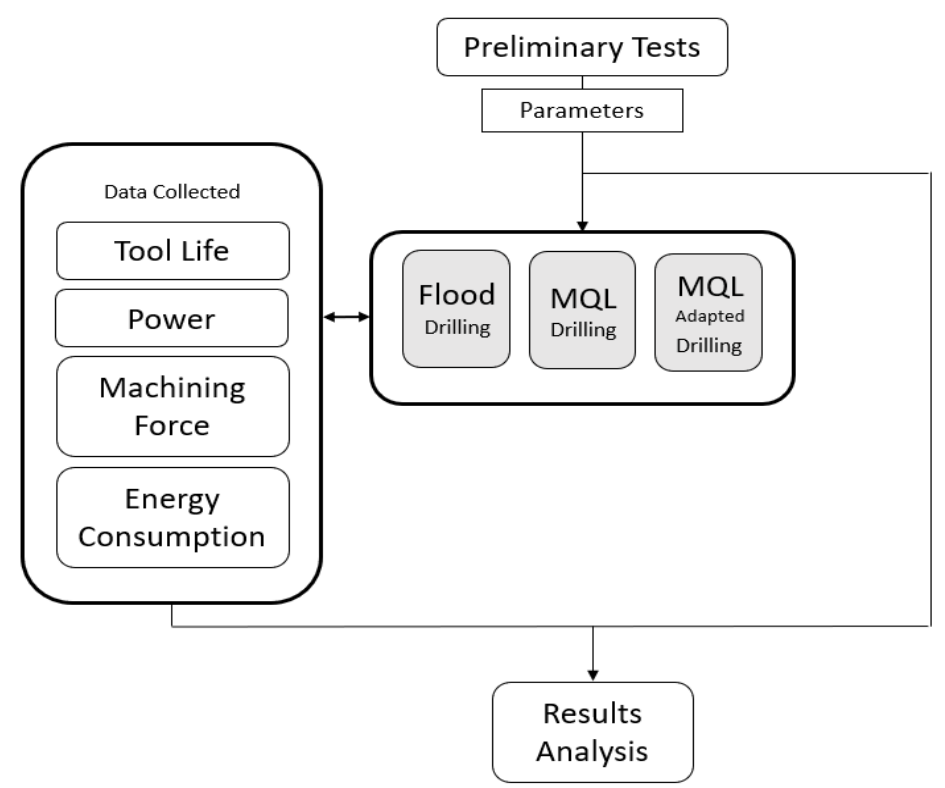

Figure 1: Flowchart test

For the definition of the parameters, a preliminary test was carried out. With the parameters defined, machining was carried out until the end of the tool's life in the three study conditions. During the machining process, the following data were monitored: tool life, machining force, energy consumption and machine power.

\subsection{Machining center}

For tests with adapted MQL, the ROMI D800 was used with a Bielomatik 1 channel system. The tests with designed MQL were performed on the GROB G550.

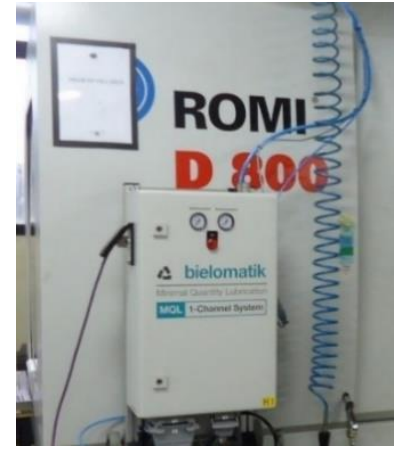

(a)

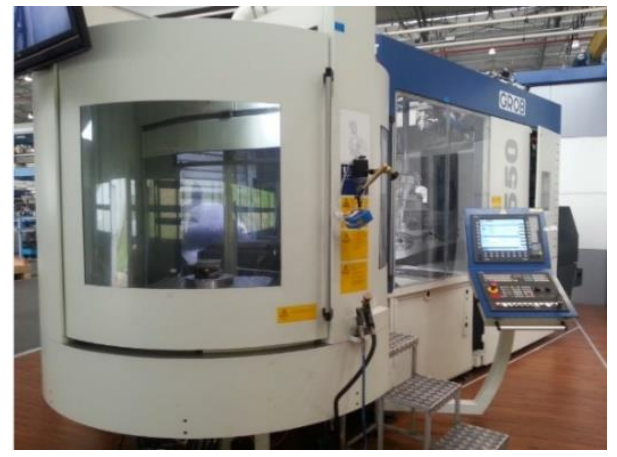

(b)

Figure 2: (a) Bielomatik single channel adapted in ROMI D800. (b) GROB Machining center GROB G550 


\subsection{Tool and work material}

The material used for testing was gray cast iron DIN GG 25 with $182 \mathrm{HB}$, this material is used in the manufacture of motors and gears.

All specimens were milled to $380 \times 240 \times 37 \mathrm{~mm}$ dimensions to ensure perpendicularity to the machine axis (Figure3 (a) and Figure 3 (b)).

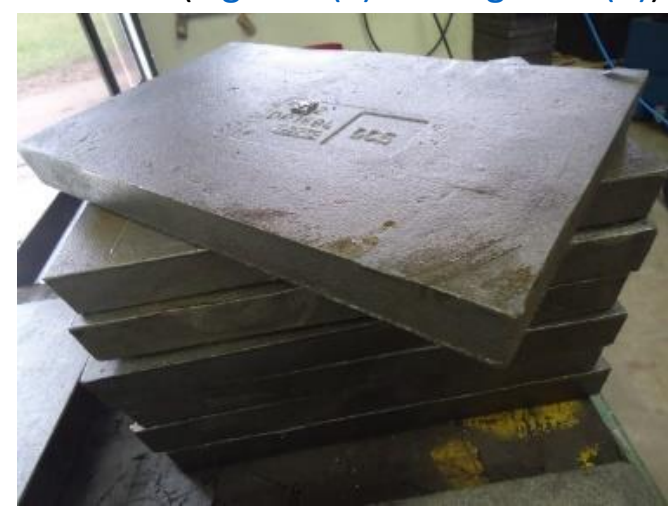

(a)

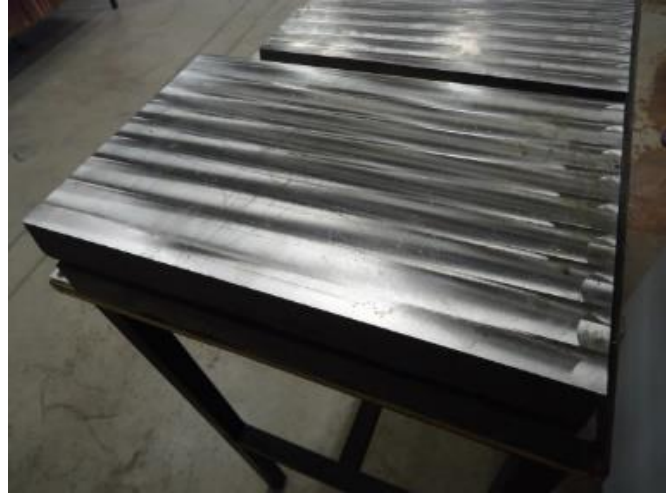

(b)

Figure 3: (a) Raw specimen. (b) Milled specimen for testing

\subsection{Parameters and tool}

In order to define machining parameters for drilling operation, dry tests were performed on the Romi D800. The selected parameters are shown in Table 1.

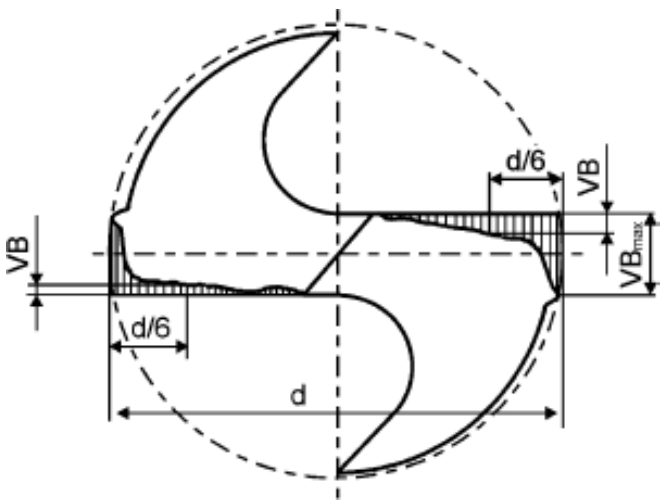

Figure 4: Criterion for defining end of tool life. Adapted from Dolinšek, Šuštaršič, and Kopač (2001)

\begin{tabular}{|c|c|}
\hline $\mathbf{V c}[\mathrm{m} / \mathrm{min}]$ & $\mathbf{f}[\mathrm{mm} / \mathbf{r o t}]$ \\
\hline 110 & 0.3 \\
\hline 110 & 0.4 \\
\hline 140 & 0.3 \\
\hline 140 & 0.4 \\
\hline
\end{tabular}

Table 1: Cutting parameters

Drilling operations were carried out with carbide drills, $13.5 \mathrm{~mm}$ diameter, 140 tip angle and TiAIN coated by Mapal. The tool's life criteria adopted was average flank wear VB(av) $=0.2 \mathrm{~mm}$, maximum flank wear $\mathrm{VB}(\max )=0.3 \mathrm{~mm}$, according to Rahim and Sasahara (2011). The measuring point on the drill is shown in Figure 4.

All drills were photographed in the new state and every specimen were machined. The images were captured with a JVC TK-C1380 video camera coupled to a Wild M3C Type-S microscope. Each drill was tagged to identify the edges. The wear was measured on both flanks. 


\subsection{Machining force}

Machining forces were measured by using Kistler's piezoelectric platform (Figure 5). For the acquisition of the machining force the data were collected with the platform while three holes were made. In order to monitor the increase in machining force with the tool wear, the force measurements were performed at each stop of wear measurement and compared with the force measured with the drills in new state. These measurements were taken every 30 holes. For each acquisition round, a new file was created in the system's interface software Dynoware Type 2825-D-02 (Figure 6). To ensure a wide range of different load intensities, all acquisitions were performed with a measuring range of $4000 \mathrm{~N}$ per amplifier channel.

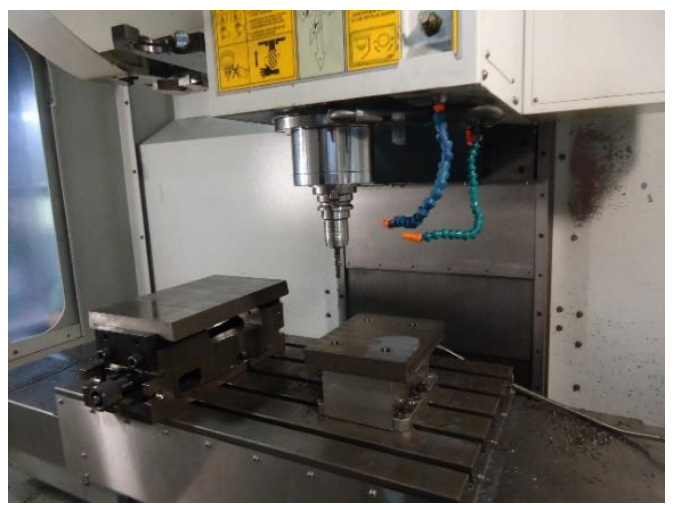

Figure 5: Kistler's piezoelectric platform

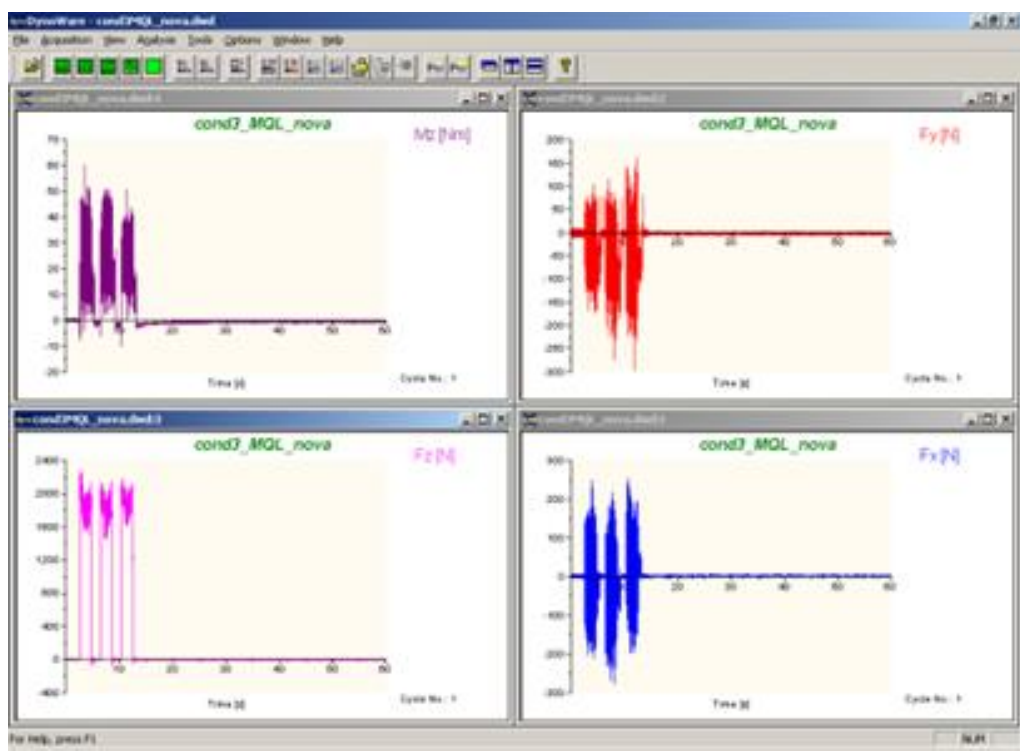

Figure 6: Software interface Dynoware Type 2825-D-02

\subsection{Energy consumption}

The required power demand was measured by using a Mult-K 120 KRON power meter and a digital magnitude transducer. LabView, which was developed in the laboratory, was used to read and organize the collected data.

The models evaluated for energy consumption are listed in Table 2. This table was adapted from Balogun and Mativenga (2013). 


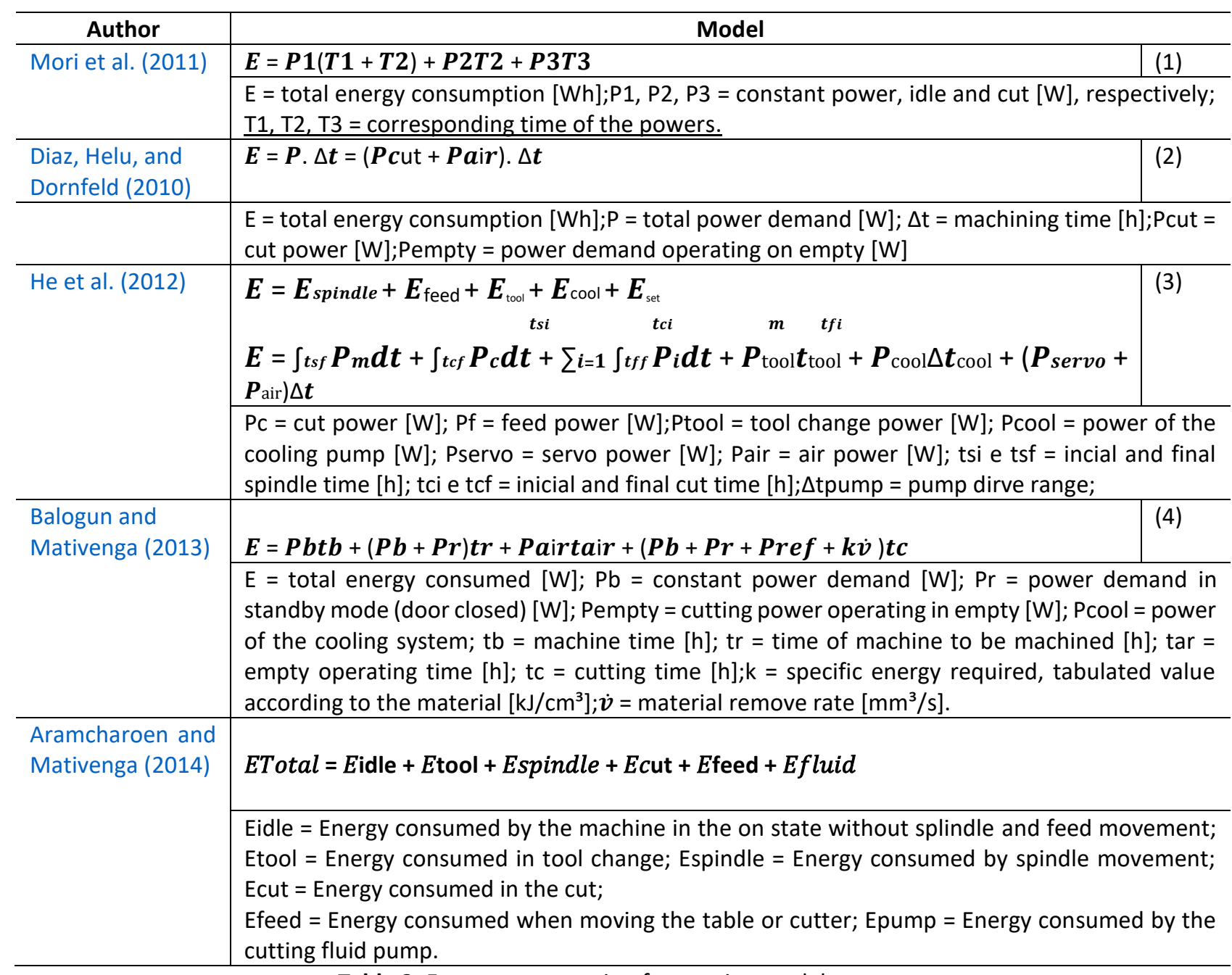

Table 2: Energy consumption forecasting models

\section{Results and Discussion}

\subsection{Tool life and force}

Tool life in the four established machining conditions was shorter with adapted MQL when compared to a machine designed for MQL. Flank wear was more pronounced in this condition (Figure 7).

One of the benefits of using MQL is a minor flank wear when compared to dry machining and flood (Dhar, Kamruzzaman, and Ahmed 2006; Özbek and Saruhan 2020). However, although the technique allows for an increase in tool life, it is important to evaluate how the application will be made, since adapted systems may have their efficiency reduced.

The MQL system utilized in the adaptation was single channel with internal feed. As the production of aerosol occurs in the tank before entering the spindle and thus being taken to the tip of the tool, leaks occur in the adaptations along the path. Consequently, there is less efficient flow in the adapted system and this loss implies poor lubrication. Thus, the shorter tool life observed in conditions with adapted MQL may have the lack of lubrication as a factor, since the application in the cutting region to cool and lubricate allows to increase the tool life (Hamran et al. 2020; Ravi, Gurusamy, and Mohanavel 2020).

The machining force was greater with the adapted MQL system when compared to the designed system. As expected, the force increased with the cutting distance due the increased flank wear observed (Figure 8). 


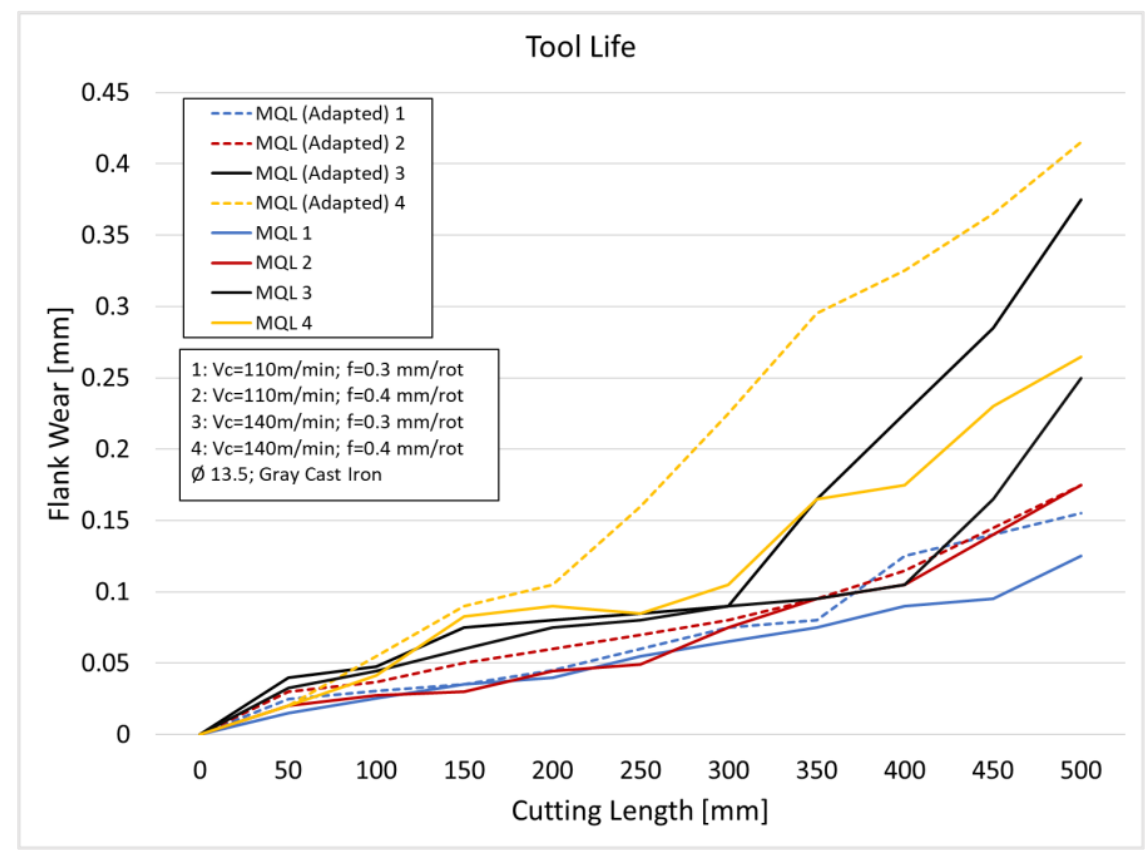

Figure 7: Flank wear for MQL adapted and projected

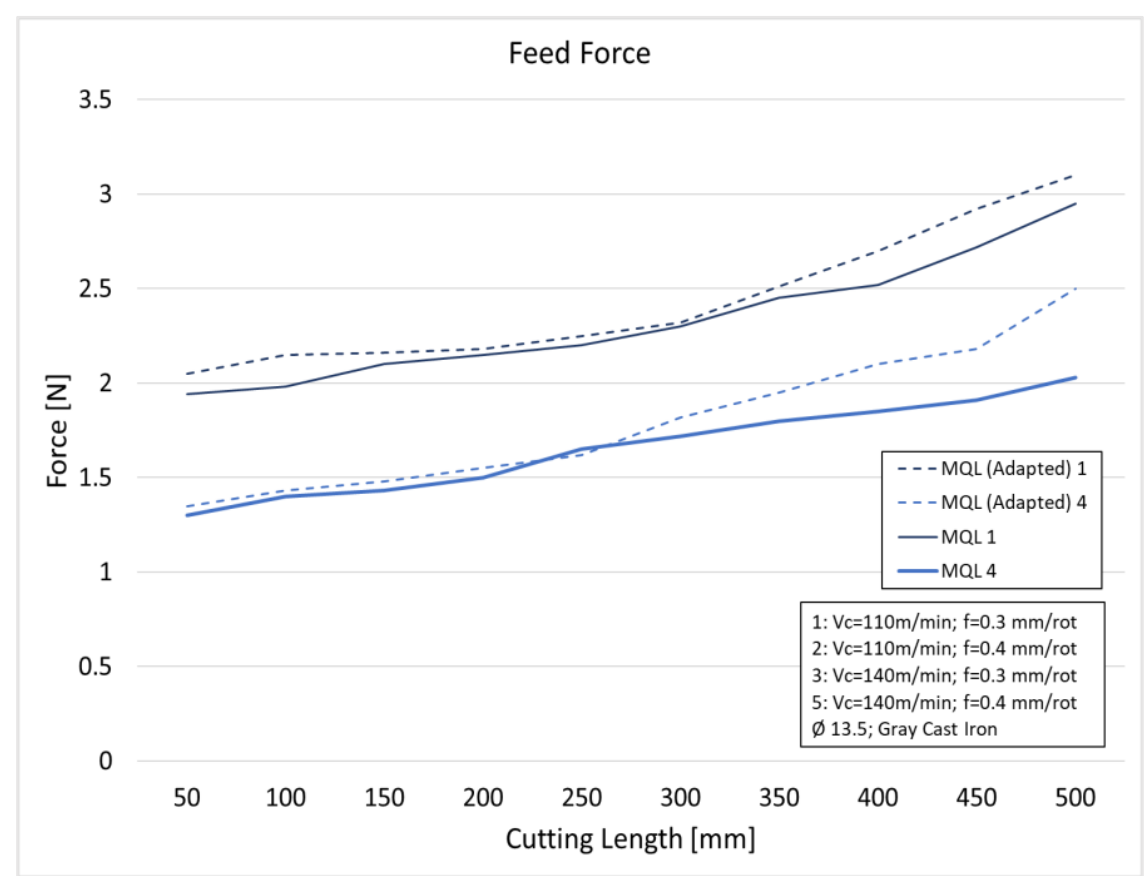

Figure 8: Feed Force $x$ Cutting Length

When analyzing the shear curve, it is possible to verify the same behavior in the flank wear curve. The difference between adapted and projected is more pronounced in condition 4, which corresponded to a greater difference in tool wear, especially at life end.

This behavior is in agreement with the shape of the measured wear, since an increase in the flank wear generates an increase in the friction of the tool/workpiece, increasing the cutting force (Machado et al. 2011).

\subsection{Energy}

The prediction of energy consumption models came closer to the measured value with flooding (Figure 9). The theoretical value was calculated according to the works of the 
respective authors (Balogun and Mativenga 2013; Aramcharoen and Mativenga 2014; Diaz, Helu, and Dornfeld 2010; He et al. 2012; Mori et al. 2011).

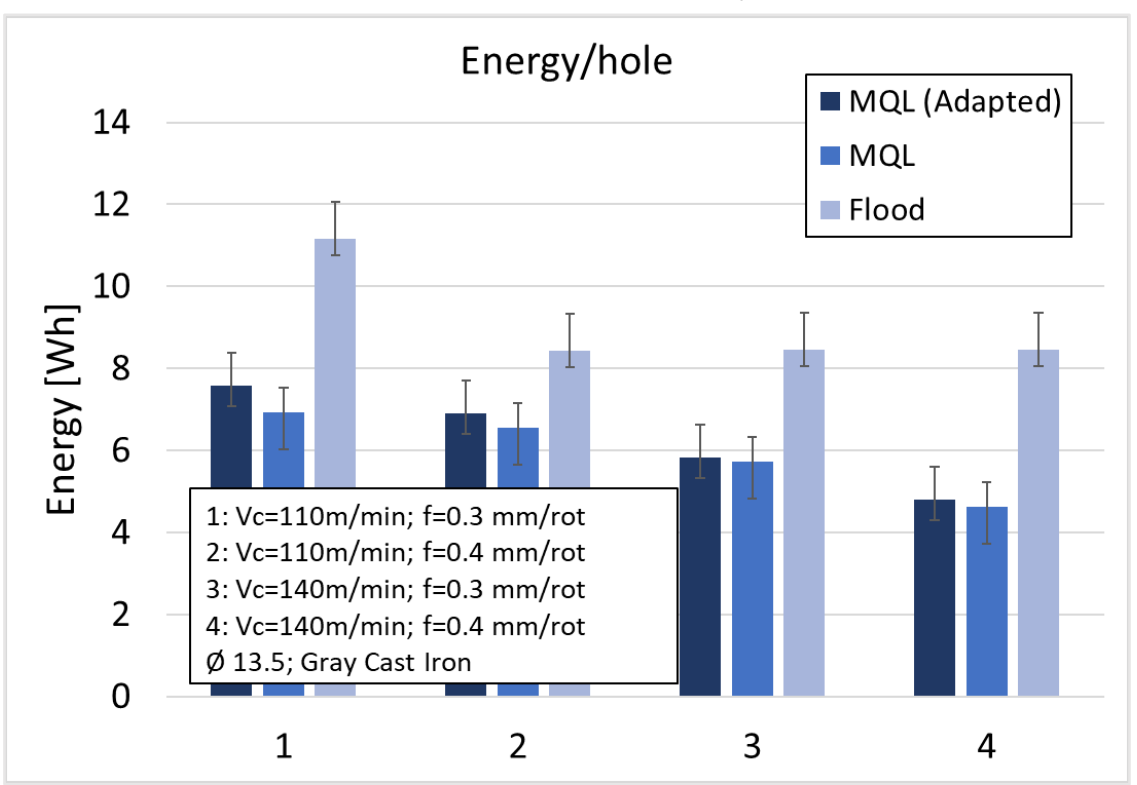

Figure 9: Energy consumption: prediction and measurement

The values were measured to make three holes with a length of $37 \mathrm{~mm}$. The energy consumption per hole, for each machining condition, is shown in Figure 10. In this assessment, the energy consumption of the compressed air was not considered, since there is no such prediction in the models studied. Considering only the energy consumption of the machining center, there is a reduction in energy consumption of $25 \%$ and $28 \%$ for machines with adapted and projected MQL system, respectively. This reduction between techniques is in accordance with the result presented by Fratila (2010) when analyzing the reduction of energy consumption in systems, in the gear milling process. The author measured a $24 \%$ reduction in energy consumption when using MQL.

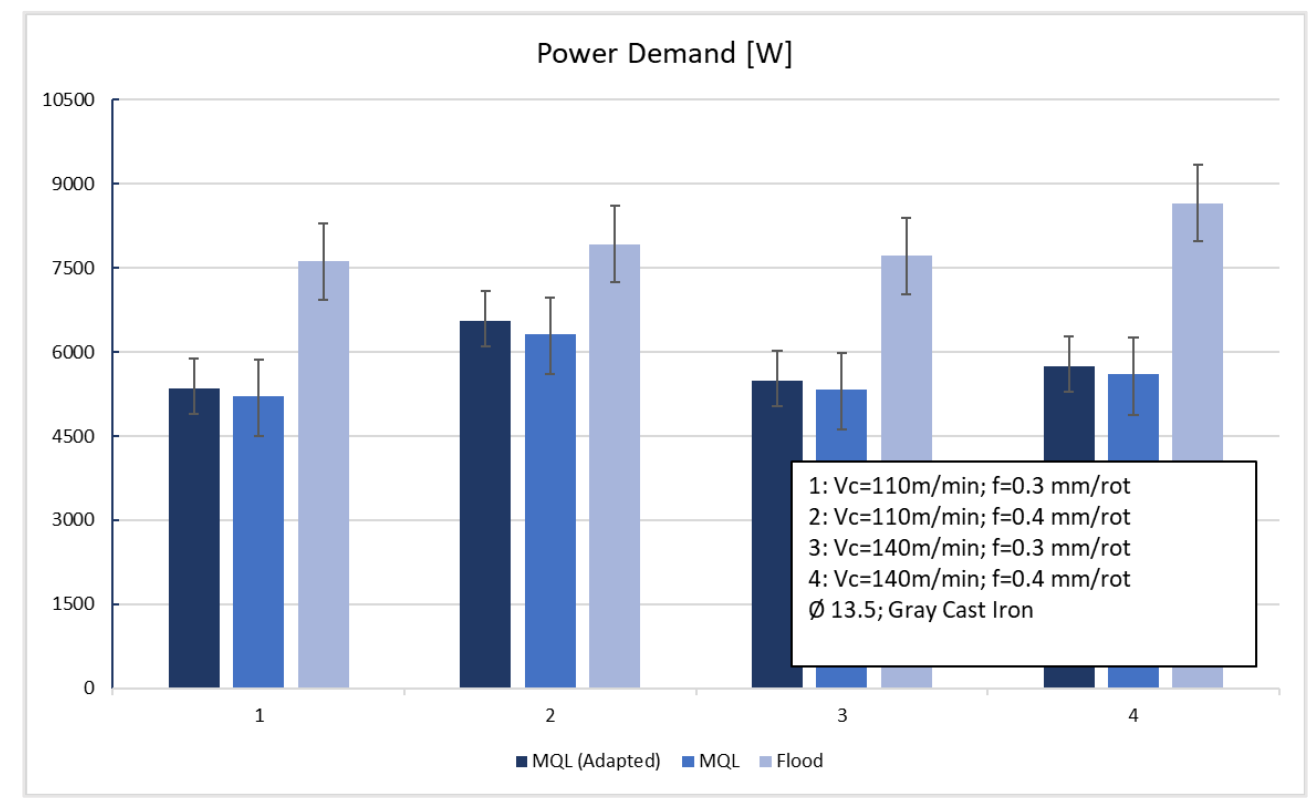

Figure 10: Energy consumption per hole

When comparing the adapted and the projected MQL, an average energy consumption reduction of 2.5 to $3 \%$ is verified for the four machining conditions. This energy consumption 
was not in proportion to the reduction in machining force. One explanation may be due to more powerful pumps for applying cutting fluid to the machine.

When analyzing the consumption of compressed air, the machining energy consumption increases in relation to the flood and the projected MQL has a significant reduction.

The operation of the laboratory air compressor is intermittent according to the compressed air use. When monitoring the compressed air power demand, it is possible to identify the activation time of the compression system motor (Figure 11). Thus, it is important to analyze the power demand with regular consumption without the MQL system connected and activated. The regular consumption was defined as the consumption necessary to maintain the compressed air without any equipment connected. When analyzing the it as performed in the article (Dttmann and Gomes 2019), it appears that the adapted MQL and projected MQL present a consumption of $34 \%$ and $14.75 \%$ higher than the regular consumption (Figure 12 ).

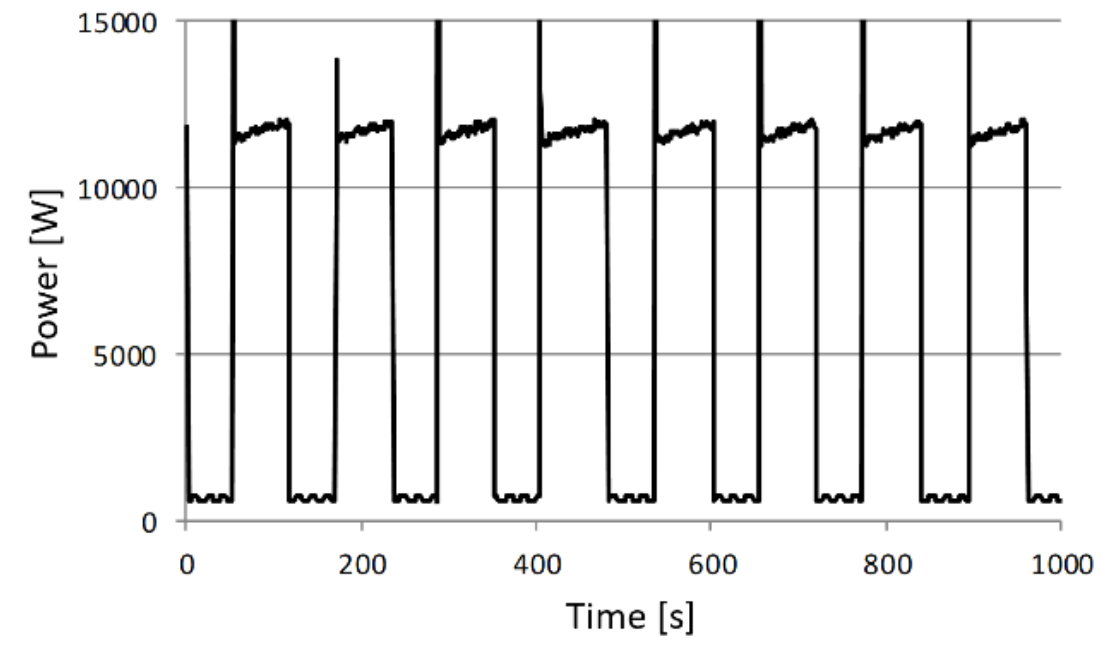

Figure 11: Curve of compressed air energy consumption

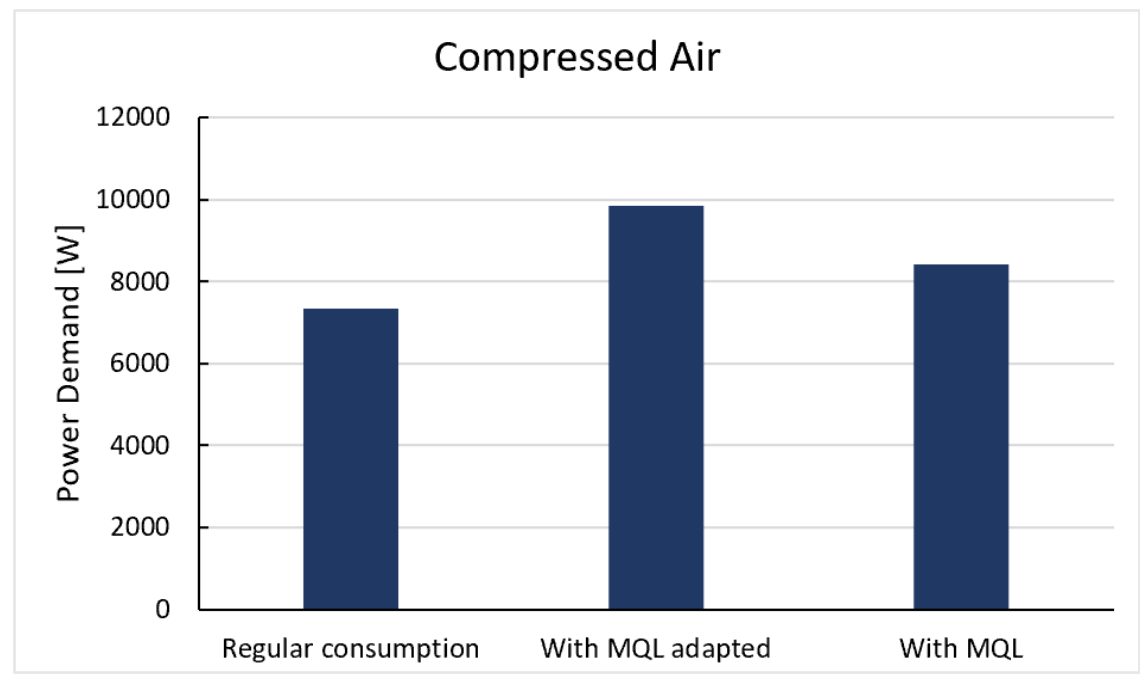

Figure 12: Power demand for compressed air

The results obtained in the tests are in accordance with Fratila (2010), where a reduction of $15-25 \%$ environmental impact was shown. The author also points to $25 \%$ reduction in the impact on operator health and $30 \%$ in resources.

For future studies, it is suggested to analyze the impact on the operator health when using adapted MQL, considering that during the tests execution with adapted MQL it was possible 
to see fog in the external region of the machine and this could affect the operator's respiratory system.

\section{Conclusion}

Analyzing the results, it is possible to find the following conclusions for each observed point:

\subsection{Tool life and force}

Tool life in the adapted center was shorter than the designed one in all machining conditions. The reduced rigidity of the adapted system may have influenced in the reduction in tool life.

\subsection{Energy consumption}

Machining centers designed for MQL are more energy efficient. This can be explained by new spindles and more modern components.

Considering only the energy consumption of the machining center, there is a reduction in energy consumption of $25 \%$ and $28 \%$ for machines with adapted and projected MQL system when compared to flood, respectively.

The machining center designed for MQL had a 2.5-3\% lower consumption than the adapted. The energy models are closer to the flood technique. The difference in consumption for MQL may be related to an under-consideration of the compressed air system.

Power demand of the compressed air system in the adapted system is $17 \%$ higher than in a projected machining center for MQL use.

\section{References}

Aramcharoen, A., and P. T. Mativenga. 2014. "Critical factors in energy demand modelling for CNC milling and impact of toolpath strategy". Journal of Cleaner Production 78: 63-74. https://doi.org/10.1016/j.jclepro.2014.04.065.

Balogun, V. A., and P. T. Mativenga. 2013. "Modelling of direct energy requirements in mechanical machining processes". Journal of Cleaner Production 41: 179-86. https://doi.org/10.1016/j.jclepro.2012.10.015.

Dhar, N. R., M. Kamruzzaman, and M. Ahmed. 2006. "Effect of minimum quantity lubrication (MQL) on tool wear and surface roughness in turning AISI-4340 steel". Journal of Materials $\begin{array}{lllll}\text { Processing } & \text { Technology } & \text { 172, } & \end{array}$ https://doi.org/10.1016/j.jmatprotec.2005.09.022.

Diaz, N, M. Helu, and D. Dornfeld. 2010. "Design and operation strategies for green machine tool development". The Proceedings of MTTRF 2010 Annual Meeting. https://escholarship.org/uc/item/613797g5\#main.

Dolinšek, S., B. Šuštaršič, and J. Kopač. 2001. "Wear mechanisms of cutting tools in high-speed cutting processes". Wear 250: 349-56. https://doi.org/10.1016/S0043-1648(01)00620-2.

Dttmann, A., and J. O. Gomes. 2019. "Energy consumption evaluation in machining centers adapted for MQL". Paper presented at the International Congress of Mechanical Engineering-COBEM 2019, Uberlândia, Brazil, October 2019. https://doi.org/10.26678/abcm.cobem2019.cob2019-1963.

Ekinovic, S., H. Prcanovic, and E. Begovic. 2015. "Investigation of influence of MQL machining parameters on cutting forces during MQL turning of carbon steel St52-3". Procedia Engineering 132: 608-14. https://doi.org/10.1016/j.proeng.2015.12.538.

Fratila, D. 2010. "Macro-level environmental comparison of near-dry machining and flood machining". Journal of Cleaner Production 18, no. 10-11: 1031-39. https://doi.org/10.1016/j.jclepro.2010.01.017. 
Fratila, D., and C. Caizar. 2012. "Investigation of the influence of process parameters and cooling method on the surface quality of AISI-1045 during turning". Materials and $\begin{array}{lllll}\text { Manufacturing } \quad \text { Processes 10: no. 1123-28. } & \end{array}$ https://doi.org/10.1080/10426914.2012.677905.

Gaurav, G., A. Sharma, G. S. Dangayach, and M. L. Meena. 2020. "Assessment of jojoba as a pure and nano-fluid base oil in minimum quantity lubrication (MQL) hard-turning of Ti-6Al4V: A step towards sustainable machining". Journal of Cleaner Production 272: 122553. https://doi.org/10.1016/j.jclepro.2020.122553.

Hamran, N. N. N., J. A. Ghani, R. Ramli, and C. H. C. Haron. 2020. "A review on recent development of minimum quantity lubrication for sustainable machining". Journal of Cleaner Production 268: 122165. https://doi.org/10.1016/j.jclepro.2020.122165.

He, Y., F. Liu, T. Wu, F. P. Zhong, and B. Peng. 2012. "Analysis and estimation of energy consumption for numerical control machining". Proceedings of the Institution of Mechanical Engineers Part B-Journal of Engineering Manufacture 226, no. B2: 255-66. https://doi.org/10.1177/0954405411417673.

Khunt, C. P., M. A. Makhesana, K. M. Patel, and B. K. Mawandiya. 2020. "Performance assessment of vegetable oil-based minimum quantity lubrication (MQL) in drilling". Materials Today: Proceedings. https://doi.org/10.1016/j.matpr.2020.09.741.

Klocke, F., and G. Eisenblätter. 1997. "Dry cutting". CIRP Annals 46, no. 2: 519-26. https://doi.org/10.1016/S0007-8506(07)60877-4.

Machado, Á. R., A. M. Abrão, R. T. Coelho, and M. B. da Sillva. 2011. Teoria da usinagem dos materiais. $2^{\text {nd }}$ ed. Blucher.

Mori, M., M. Fujishima, Y. Inamasu, and Y. Oda. 2011. "A study on energy efficiency improvement for machine tools". CIRP Annals-Manufacturing Technology 60, no. 1: 14548. https://doi.org/10.1016/j.cirp.2011.03.099.

Özbek, O., and H. Saruhan. 2020. "The effect of vibration and cutting zone temperature on surface roughness and tool wear in eco-friendly MQL turning of AISI D2". Journal of Materials Research and Technology 9, no. 3: 2762-72. https://doi.org/10.1016/j.jmrt.2020.01.010.

Rahim, E. A., and H. Sasahara. 2011. "A study of the effect of palm oil as MQL lubricant on high speed drilling of titanium alloys". Tribology International 44, no. 3: 309-17. https://doi.org/10.1016/j.triboint.2010.10.032.

Ravi, S., P. Gurusamy, and V. Mohanavel. 2020. "A review and assessment of effect of cutting fluids". Materials Today: Proceedings. https://doi.org/10.1016/j.matpr.2020.05.054.

Sarikaya, M., and A. Güllü. 2014. "Taguchi design and response surface methodology based analysis of machining parameters in CNC turning under MQL". Journal of Cleaner Production 65: 604-16. https://doi.org/10.1016/j.jclepro.2013.08.040.

Sharma, V. S., M. Dogra, and N. M. Suri. 2009. "Cooling techniques for improved productivity in turning". International Journal of Machine Tools \& Manufacture 49, no. 6: 435-53. https://doi.org/10.1016/j.ijmachtools.2008.12.010.

Umbrello, D., F. Micari, and I. S. Jawahir. 2012. "The effects of cryogenic cooling on surface integrity in hard machining: A comparison with dry machining". CIRP Annals-Manufacturing Technology 61, no. 1: 103-06. https://doi.org/10.1016/j.cirp.2012.03.052. 